\title{
Knowledge about research publication: A comparative study among dental postgraduate students
}

\author{
Ishani Chawla ${ }^{1, *}$, Ipseeta Menon ${ }^{2}$, Ricky Pal Singh ${ }^{3}$, Anubhav Sharma ${ }^{4}$ \\ ${ }^{1}$ Post graduate Student, ${ }^{2}$ Professor, ${ }^{3}$ Reader, ${ }^{4}$ Senior Lecturer, Dept. of Public Health Dentistry, I. T. S Centre for Dental Studies \\ and Research, Muradnagar, Ghaziabad, Uttar Pradesh, India
}

*Corresponding Author:

Email: dr.ishanichawla@gmail.com

\begin{abstract}
Aim: To evaluate the knowledge of dental postgraduate students regarding publication of research papers.

Materials and Methods: This was a questionnaire based comparative study in which after ethical approval the 2 groups compromising 30 post graduates students each( Group 1 = exam going final year Post Graduates, Group $2=$ Post Graduates who just entered final year) were selected from a dental institution by simple random sampling. Then their knowledge regarding research publication was assessed using a self administered questionnaire.

Results: The post graduates appearing for the exam has higher knowledge scores (mean score $=5.87 \pm 2.44)$ regarding research publication as compared to those who just entered the final year as their mean knowledge score (mean score $=7.10 \pm 2.46$ ).

Conclusion: This study pinpoints the deficiencies in knowledge among Post graduates about research publication. To benefit the latter workshops and lectures on research publication should be made, part of post graduate curriculum so that they would be in ease during conducting and publishing their work without getting involved in fraudulent affairs.
\end{abstract}

Keywords: Research publication, Comparative study, Dental post graduate students.

\section{Introduction}

In an era of evidence based medicine where everything changes in flip of a second, research laid an important innovation stone behind all this success and an end product of any scientific research is publication. ${ }^{1}$ The knowledge about publishing the research work lack most in the students and moreover due to increases fraudulent practices students land up in more dilemma about the proper channel through which they can publish their works. ${ }^{2}$

Research itself is a complex integrity that involve many core terms and protocol. According to previous literatures $10 \%$ to $15 \%$ of total researchers in their lifetime are involved in inappropriate research practices and misconduct, therefore if we want a quality work and want to contribute in medical health research by our work, the knowledge about these protocols of conducting and publishing research is mandatory. Although international bodies like COPE has given a proper subset of guidelines of writing and publishing research but it is usually in appropriately practice in our country. ${ }^{3,4}$

The guidelines for publishing the research works are also provided by the specific journals according to their norms on their journal pages so to ease in following those instructions it is necessary to be well versed with scientific terms and one should be in a habit of writing research in the standardize protocols only. ${ }^{5}$

Moreover we agree due to complexity of research no one can accomplish the total concept of it but the terms like Scopus, Pubmed, Google Scholar, Ebsco, ISI should be in the vocabulary of the students and the benefits of publishing between indexed and non indexed journal should be transparent in their mind. Once the concepts are clear the difficulty level drops and getting into fraud practices and being cheated also become negligible. ${ }^{6}$

Research is always a team work and there is serious lacking in this effort. So there should be formal training to make the post graduates aware of unseen horizons of research publication. ${ }^{7}$ Therefore, this study was conducted to review the knowledge of post graduates about research publications and then, accordingly design the reforms needed in imparting knowledge about the same after assessing them.

\section{Materials and Methods}

This is a questionnaire based comparative survey in which 2 groups of postgraduate students studying in dental institution were selected using convenient sampling after the approval from the ethical committee. The pilot study was conducted on 10 post graduate student in each group to draw the sample size and to validate the self administered questionnaire (Cronbach's alpha coefficient-0.78). ${ }^{4}$ The sample size was drawn using sample size calculation software, taking in account the total target population with expected frequency of $50 \%$ in each group and $95 \%$ confidence interval, and the total target population of post graduate student which was 50 in each year. ${ }^{5} \mathrm{~A}$ random sampling was done to select the subjects till the desired sample size is obtained. The group one comprised 30 dental postgraduate students who were appearing for their final exams and the second group also comprised of 30 dental post graduate students, who just the entered the final year.

The students who gave the written consent were only included in the study and those students who were absent at time of data collection were excluded from the 
study. The data regarding the knowledge of research publication among dental post graduate students was collected by direct interview method. The questionnaire consists of two parts, first one contains demographic details and second part consists of 14 questions aimed at assessing the knowledge regarding research publication.

Each question was allotted a score of 1 for right answer, then the total score for each student was calculated by adding the scores, the maximum score for each individual is 14 and minimum 0 . Thereafter the mean score of the groups was assessed to compare the knowledge status among the two selected groups. The data once collected was analyzed using SPSS version 22. Descriptive statistics was applied to draw the results including descriptive statitics and non parametric test like Mann Whitney to compare the knowledge regarding publication in two groups.

\section{Results}

Total 60 post graduate students were enrolled in the present study, out of which 30 post graduates ( 20 females and 10 males) who just entered the final year constituted the first group. Similarly, 30 students who were appearing for the exam constituted the group 2 (18 females and 12 males). All the participants were in the age group of 27 to 30 years.
A total of $40(66.6 \%)$ out of 60 post graduate students were aware of the indexing of journals, among them $18(45 \%)$ belong to group 1 and 22(55\%) belong to group 2. $41(68.3 \%)$ students out of 60 agree that there is benefit of publishing the article in indexed journal over non indexed journal out of which 17(41.5\%) were from group 1 and 24(58.5\%) were from group 2. 40 out of 60 post graduates were not aware of the term impact factor of an article and its significance out of these $40(66.6 \%)$ students $21(52.5 \%)$ belong to group 1 and 19(47.5\%) belong to group 2. Out of 60 students, those who were aware of plagiarism were 41(68.3\%) and tools for research writing were $29(48.3 \%) .43(71.6 \%)$ out of 60 students were unaware of the ethical protocols approved by the higher bodies for research publication.

The perception about research was also lacking as $42(70 \%)$ out of 60 post graduate found that, research usefulness is limited to academics only. $49(81.6 \%)$ out of 60 agreed that they lacked to maintain research quality and at some time fell a prey of fraudulent practices such as ghost authorship and gifting authorship (Table 1).

The post graduate students in group 2 had higher mean score of knowledge 7.10 \pm 2.4 as compared to group 1 whose mean score was $5.87 \pm 2.4$ and the difference between the results of knowledge score between two group is statistically significant as ( $p$ value $=0.020$ ) on application of Mann Whitney Non parametric test (Table 2).

Table 1: Comparison between two groups of post graduates regarding their knowledge scores

\begin{tabular}{|c|c|c|c|c|}
\hline Questions & Responses & $\begin{array}{c}\text { GROUP 1 } \\
\text { (Just Entered } \\
\text { final year) }\end{array}$ & $\begin{array}{c}\text { GROUP 2 } \\
\text { (Exam going } \\
\text { Final year) }\end{array}$ & Total \\
\hline \multirow{2}{*}{$\begin{array}{l}\text { Question } 1 \text { Are you aware of journal } \\
\text { indexing? }\end{array}$} & $\mathrm{NO}$ & $12(60 \%)$ & $8(40 \%)$ & $20(33.3 \%)$ \\
\hline & YES & $18(45 \%)$ & $22(55 \%)$ & $40(66.6 \%)$ \\
\hline \multirow{2}{*}{$\begin{array}{l}\text { Question } 2 \text { Is there any benefit of getting } \\
\text { article publish in indexed over non indexed } \\
\text { journal? }\end{array}$} & NO & $13(68.4 \%)$ & $6(31.6 \%)$ & $19(31.6 \%)$ \\
\hline & YES & $17(41.5 \%)$ & $24(58.5 \%)$ & $41(68.3 \%)$ \\
\hline \multirow{2}{*}{$\begin{array}{l}\text { Question } 3 \text { Do you the significance of } \\
\text { Impact factor? }\end{array}$} & $\mathrm{NO}$ & $21(52.5 \%)$ & $19(47.5 \%)$ & $40(66.6 \%)$ \\
\hline & YES & $9(45 \%)$ & $11(55 \%)$ & $20(33.3 \%)$ \\
\hline \multirow[t]{2}{*}{ Question 4 Do you know what is i10 index? } & NO & $21(52.5 \%)$ & $19(47.5 \%)$ & $40(66.6 \%)$ \\
\hline & YES & $9(45 \%)$ & $11(55 \%)$ & $20(33.3 \%)$ \\
\hline \multirow[t]{2}{*}{ Question 5 Do you know what is $\mathrm{h}$ index? } & NO & $21(52.5 \%)$ & $19(47.5 \%)$ & $40(66.6 \%)$ \\
\hline & YES & $9(45 \%)$ & $11(55 \%)$ & $20(33.3 \%)$ \\
\hline \multirow{2}{*}{$\begin{array}{l}\text { Question } 6 \text { Are you aware of the process of } \\
\text { getting the article published? }\end{array}$} & NO & $18(58.1 \%)$ & $13(41.9 \%)$ & $31(51.6 \%)$ \\
\hline & YES & $12(41.4 \%)$ & $17(58.6 \%)$ & $29(48.3 \%)$ \\
\hline \multirow[t]{2}{*}{ Question 7 Are you aware of plagiarism? } & NO & $9(47.4 \%)$ & $10(52.6 \%)$ & $19(31.6 \%)$ \\
\hline & YES & $21(51.2 \%)$ & $20(48.8 \%)$ & $41(68.3 \%)$ \\
\hline \multirow{2}{*}{$\begin{array}{l}\text { Question } 8 \text { Are you aware of formats } \\
\text { available to write down the research article? }\end{array}$} & NO & $18(58.1 \%)$ & $13(41.9 \%)$ & $31(51.6 \%)$ \\
\hline & YES & $12(41.4 \%)$ & $17(58.6 \%)$ & $29(48.3 \%)$ \\
\hline \multirow{2}{*}{$\begin{array}{l}\text { Question } 9 \text { Are you aware of latest tools } \\
\text { that aid you in conducting/writing research } \\
\text { article? }\end{array}$} & NO & $20(51.3 \%)$ & $19(48.7 \%)$ & $39(65 \%)$ \\
\hline & YES & $10(47.6 \%)$ & $11(52.4 \%)$ & $21(35 \%)$ \\
\hline \multirow{3}{*}{$\begin{array}{l}\text { Question } 10 \text { Do you know why journal has } \\
\text { a different publication points as per DCI? }\end{array}$} & NO & $22(53.7 \%)$ & $19(46.3 \%)$ & $41(68.3 \%)$ \\
\hline & YES & $8(42.1 \%)$ & $11(57.9 \%)$ & $19(31.6 \%)$ \\
\hline & NO & $23(69.7 \%)$ & $10(30.3 \%)$ & $33(55 \%)$ \\
\hline
\end{tabular}




\begin{tabular}{|l|c|c|c|c|}
\hline $\begin{array}{l}\text { Question 11 Have you ever undergone } \\
\text { fraudulent practice during your research } \\
\text { publication? }\end{array}$ & YES & $7(25.9 \%)$ & $20(74.1 \%)$ & $27(45 \%)$ \\
\hline $\begin{array}{l}\text { Question 12 Is research is for academic } \\
\text { purpose only? }\end{array}$ & NO & $9(50 \%)$ & $9(50 \%)$ & $18(30 \%)$ \\
\cline { 2 - 5 } & YES & $21(50 \%)$ & $21(50 \%)$ & $42(70 \%)$ \\
\hline $\begin{array}{l}\text { Question 13 Are you aware of ethics in } \\
\text { publication about Authorship? }\end{array}$ & NO & $23(53.5 \%)$ & $20(46.5 \%)$ & $43(71.6 \%)$ \\
\cline { 2 - 5 } & YES & $7(41.2 \%)$ & $10(58.8 \%)$ & $17(28.3 \%)$ \\
\hline $\begin{array}{l}\text { Question 14 Do you think you do a quality } \\
\text { research? }\end{array}$ & NO & $26(53.1 \%)$ & $23(46.9 \%)$ & $49(81.6 \%)$ \\
\cline { 2 - 5 } & YES & $4(36.4 \%)$ & $7(63.6 \%)$ & $11(18.3 \%)$ \\
\hline
\end{tabular}

Table 2: Comparison between mean of total scores of knowledge regarding research publication in study groups

\begin{tabular}{|l|c|c|c|}
\hline \multicolumn{1}{|c|}{ Groups } & $\begin{array}{c}\text { Knowledge score } \\
(\text { Mean } \pm \text { S.D) }\end{array}$ & $\begin{array}{c}\text { Std. Error of } \\
\text { Mean }\end{array}$ & p-value \\
\hline Group 1 (Entered Final Year) & $5.87 \pm 2.44$ & .447 & \multirow{2}{*}{$0.020^{*}$} \\
\hline Group 2 (Exam Going Final Year) & $7.10 \pm 2.46$ & .451 & \\
\hline
\end{tabular}

(Mann Whitney test*)

\section{Discussion}

The objective of this study was to evaluate the knowledge of two groups of post graduates student regarding research publication and our results of the study signifies that the postgraduate student who were exam going had better knowledge score as compared to post graduates who just entered the final year. This difference is also statistically significant, because the post graduates who were appearing for the exams had already done their research work published and been exposed to all this criteria while publishing their works. Similar results have also been reported by Jahanfar $\mathrm{S}$ et al. in their study. ${ }^{5}$

Although most of students were aware of indexing of journals but the fact of getting article published in indexed journal is still not clear to most of the post graduates. The term like $\mathrm{h}$ index (Hirsch index) and i10 index introduced by Google scholar in 2011 for measuring the productivity and citation impact factor of a scholar is far unknown to the postgraduates because formal training in research methodology and publication ethics is lacking in the post graduates curriculum and similar results quoted by Das KK et al. ${ }^{6}$ and Robert et al. ${ }^{7}$ in their study.

The training of medical and dental students should be made a mandatory at both undergraduate and postgraduate level by adding it in their course curricula even the general medical council report on medical education recommends its inclusion. ${ }^{8,9}$

Lacking the knowledge about latest tools that aids in conducting, writing and publishing research work make the research a complex procedure ${ }^{10}$ and this further lead to lack of interest in research work as most of the postgraduates students only find its utility limited to academic success only and similar result was also quoted by Clement TP in his study. ${ }^{11,12}$

As according to American Psychological Association $\mathrm{APA}^{13}$ and American Counseling Association ACA suggest stress free environment for research publication and mandatory guidance by faculty members to the students for maintaining the quality of research and minimizing the fraudulent practices. ${ }^{14-16}$

Due to lack of knowledge and complexity of research work laden with disputes during publication and authorships all degraded the quality of research work similar was quoted by Tschamkte T et al. ${ }^{17}$ and Hren et al. ${ }^{18}$ in their study.

The researchers should focus on quality of research, inspite of the hurdles and a regulatory body should be made to govern the quality of research conducted and published. ${ }^{19,20}$ The proper training of the post graduates should be done in research methodology, latest tools, and ethics of publication so that they don't fell prey to such practices and can easily get their work credited to their name and published..$^{21,22}$

The finding of this study could be a footstep, in evaluating knowledge about the research publication in the students and reforms needed in improving the quality of research, further studies can be done in future comparing the groups from different strata to explore the differences.

\section{Conclusion}

The deficiencies pinpointed by this study regarding knowledge of research publication should be taken in account and appropriate measures like lectures and workshop should be conducted for post graduates to enhance their knowledge and to make them at ease with this publication procedure with the suggestion of making it a mandatory in postgraduate protocol. The limitation of the study was that the sample should be drawn from different institutes to increase the external validity of the study.

\section{Acknowledgement}

We would like to thank the postgraduate students who spared their precious time to participate in the study.

Conflict of Interest: None. 


\section{References}

1. Shirazi B, Jafarey AM, Moazam F. Plagiarism and the medical fraternity: A study of knowledge and attitudes. $J$ Pak Med Assoc 2010;60(1):269-73.

2. Mubeen S, Qurrat-ul-Ain, Ghayas R, Adil Rizvi S, Khan $\mathrm{S}$. Knowledge of scientific misconduct in publication among medical students. Educ health (Abingdon) 2017;30(2):140- 44.

3. Dooley JJ, Kerch HM. Evolving research misconduct policies and their significance for physical scientists. Sci Eng Ethics 2000;6:109-21.

4. Committee on Publication Ethics (COPE). Guidelines on good publication practice the COPE report 2003. Indian J Pharmacol 2005;37:199-203.

5. Jahanfar S, Molainejad M, Izzat D. Knowledge and Perception of Students towards Publication Ethics: A Comparative Study in Two Academic Settings. J Clin Res Bioeth 2017;08(03):156-60.

6. Kanti Das K, Vallabha T, Mahesh Patil S, Ray J, Kumar Deepak K. Knowledge on Ethical Authorship: A Comparative Study Between Medical And Pharmacy Faculty. J Young Pharm 2016;8(2):136-40.

7. Roberts J. An author's guide to publication ethics: a review of emerging standards in biomedical journals. Headache 2009;49(4):578-89.

8. American Counseling Association Code of ethics. Aust $N$ Z J Psychiatry 2014; 26: 677-78.

9. Tomorrow's Doctors-Outcomes and standards for undergraduate medical education. 1st ed. General Medical Council; 2009.

10. Aggrawal R, Kapoor VK. Scientific writing of medical personnel in India: An evaluation. Natl Med J India 2004; 17(2)118-17

11. Clement TP. Authorship matrix: a rational approach to quantify individual contributions and responsibilities in multi-author scientific articles. Sci Eng Ethics 2014;20(2): 345-61.
12. AAMFT Code of Ethics American Association for Marriage and Family Therapy;2015.

13. APA Ethics Committee Rules and Procedures;2016.

14. ACA American Counseling Association;2016.

15. Rennie D, Yank V, Emanuel L. When authorship fails. A proposal to make contributors accountable. JAMA 1997;278(7):579-85.

16. Flanagin A, Carey LA, Fontanarosa PB. Prevalence of articles with honorary authors and ghost authors in peer reviewed medical journals. JAMA 1998; 280(3):222-24.

17. Tschamtke T, Hochberg ME, Rand TA, Resh VH, Krauss $\mathrm{J}$. Authors sequence and credit for contribution in multi authored publications. PLoSBiol 2007;5(1):18-21.

18. Hren D, Sambunjak D, Ivanis A, Marusic M, Marusic A. Perceptions of authorship criteria: effects of student instruction and scientific experience. J Med Ethics 2007;33(1): 428-432.

19. Rennie D, Yank V, Emanuel L. When authorship fails. A proposal to make contributors accountable. JAMA 1997;278(7):579-85.

20. Gasparyan AY, Nurmashev B, Voronov AA, Gerasimov AN, Koroleva AM, Kitas GD. The pressure to publish more and the scope of predatory publishing activities. $J$ Korean Med Sci 2016; 31(1):1874-78.

21. Ghias K, Lakho GR, Asim H, Azam IS, Saeed SA. Self reported attitudes and behaviours of medical students in Pakistan regarding academic misconduct: A cross sectional study. BMC Med Ethics 2014;15:43-47.

How to cite the article: Chawla I, Menon I, Singh RP, Sharma A. Knowledge about Research Publication: A Comparative Study among Dental Postgraduate Students. J Dent Specialities 2018;6(2):156-159. 